cardiopulmonary bypass has to be ready, even if it should be reserved for salvage, because of recent neurologic lesions that are often associated. We preferred an off-pump strategy via a lateral thoracotomy, rather than a sternotomy, for an elective intracardiac repair. The choice of the left side for the approach was based on left pleural effusion draining the mediastinal infection, but a right access to the esophagus is also feasible. The esophageal repair or esophagectomy is chosen according to the local severity of necrosis and mediastinitis. A pericardial flap was easy and efficient to separate the atrial and esophageal sutures, correcting the natural pericardial defect that caused AEF after CA.

\section{References}

1. Cappato R, Calkins H, Chen SA, Davies W, Iesaka Y, Kalman J, et al. Prevalence and causes of fatal outcome in catheter ablation of atrial fibrillation. $J$ Am Coll Cardiol. 2009;53:1798-803.

2. Grande L, Lacima G, Ros E, Pera M, Ascaso C, Visa J, et al. Deterioration of esophageal motility with age: a manometric study of 79 healthy subjects. Am J Gastroenterol. 1999; $94: 1795-801$.

3. Doll N, Borger MA, Fabricius A, Stephan S, Gummert J, Mohr FW, et al. Esophageal perforation during left atrial radiofrequency ablation: is the risk too high? J Thorac Cardiovasc Surg. 2003;125:836-42.

4. Bunch TJ, Nelson J, Foley T, Allison S, Crandall BG, Osborn JS, et al. Temporary esophageal stenting allows healing of esophageal perforations following atrial fibrillation ablation procedures. J Cardiovasc Electrophysiol. 2006;17:435-9.

5. Pappone C, Oral H, Santinelli V, Vicedomini G, Lang CC, Manguso F, et al. Atrioesophageal fistula as a complication of percutaneous transcatheter ablation of atrial fibrillation. Circulation. 2004;109:2724-6.

\title{
Lower graft patency after off-pump than on-pump coronary artery bypass grafting: An updated meta-analysis of randomized trials
}

\author{
Hisato Takagi, MD, PhD, Masafumi Matsui, MD, and Takuya Umemoto, MD, PhD, Shizuoka, Japan
}

Our previous meta-analysis of randomized trials demonstrated a significant increase in overall graft occlusion, especially in saphenous vein graft occlusion, in off-pump coronary artery bypass grafting (CABG) compared with on-pump CABG. ${ }^{1}$ Since we conducted the meta-analysis, graft patency in several randomized trials has been reported. The likelihood of graft occlusion was no different between off-pump and on-pump CABG groups in a study by Angelini and associates, ${ }^{2}$ whereas Shroyer and collaborators ${ }^{3}$ revealed that the overall rate of graft patency was lower in the off-pump group than in the on-pump group. We performed an updated meta-analysis of graft patency after offpump versus on-pump CABG from randomized trials.

\section{CLINICAL SUMMARY}

All prospective randomized controlled trials that compared graft patency of 3 or more months after off-pump versus on-pump CABG were identified using a 2-level search strategy. First, a public domain database (MEDLINE) was

\footnotetext{
From the Department of Cardiovascular Surgery, Shizuoka Medical Center, Shizuoka, Japan.

Disclosures: None.

Received for publication Nov 9, 2009; accepted for publication Nov 22, 2009; available ahead of print Jan 14, 2010.

Address for reprints: Hisato Takagi, MD, PhD, Department of Cardiovascular Surgery, Shizuoka Medical Center, 762-1 Nagasawa, Shimizu-cho, Sunto-gun, Shizuoka 411-8611, Japan (E-mail: kfgth973@ybb.ne.jp).

J Thorac Cardiovasc Surg 2010;140:e45-7

$0022-5223 / \$ 36.00$

Copyright $(C) 2010$ by The American Association for Thoracic Surgery

doi:10.1016/j.jtcvs.2009.11.045
}

searched with a Web-based search engine (PubMed). Second, relevant studies were identified through a manual search of secondary sources, including references of initially identified articles and a search of reviews and commentaries. The MEDLINE database was searched from January 1966 to October 2009. Exploding keywords included "off-pump," "off pump," “opcab," “patency," and "randomized trial." Studies considered for inclusion met the following criteria: The design was a prospective randomized controlled clinical trial; patients were randomly assigned to off-pump or on-pump CABG; and main outcomes included graft patency of 3 or more months. Data regarding detailed inclusion criteria; duration of follow-up; and internal thoracic artery, saphenous vein, and overall graft patency were abstracted from each individual study. For each study, data regarding patency in both the off-pump and on-pump $\mathrm{CABG}$ groups were used to generate risk ratios (RRs) for graft occlusion $(<1$, favors off-pump CABG; $>1$, favors on-pump CABG) and 95\% confidence intervals (CIs). Study-specific estimates were combined with inverseweighted averages of logarithmic RRs in both fixed- and random-effects models. Between-study heterogeneity was analyzed by means of standard chi-square tests. Where no significant statistical heterogeneity was identified, the fixed-effects estimate was used preferentially as the summary measure. Sensitivity analyses were performed to assess the contribution of each study to the pooled estimate by excluding individual trials one at a time and recalculating the pooled RR estimates for the remaining studies. To assess the impact of differential length of follow-up on the pooled 


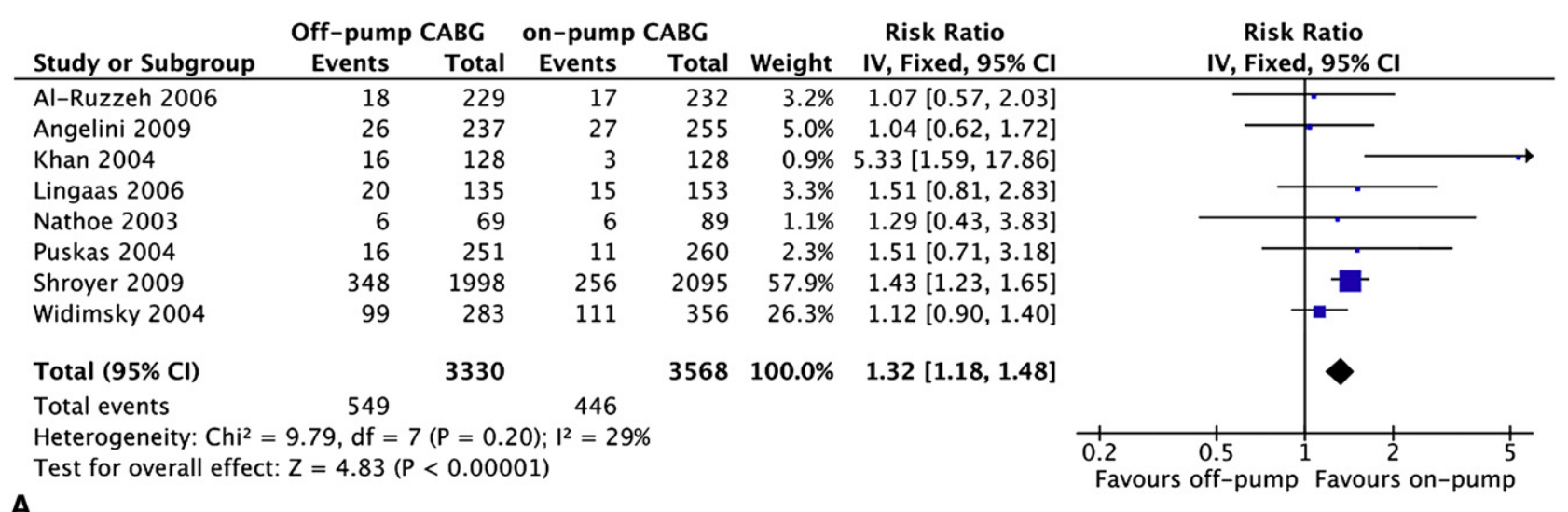

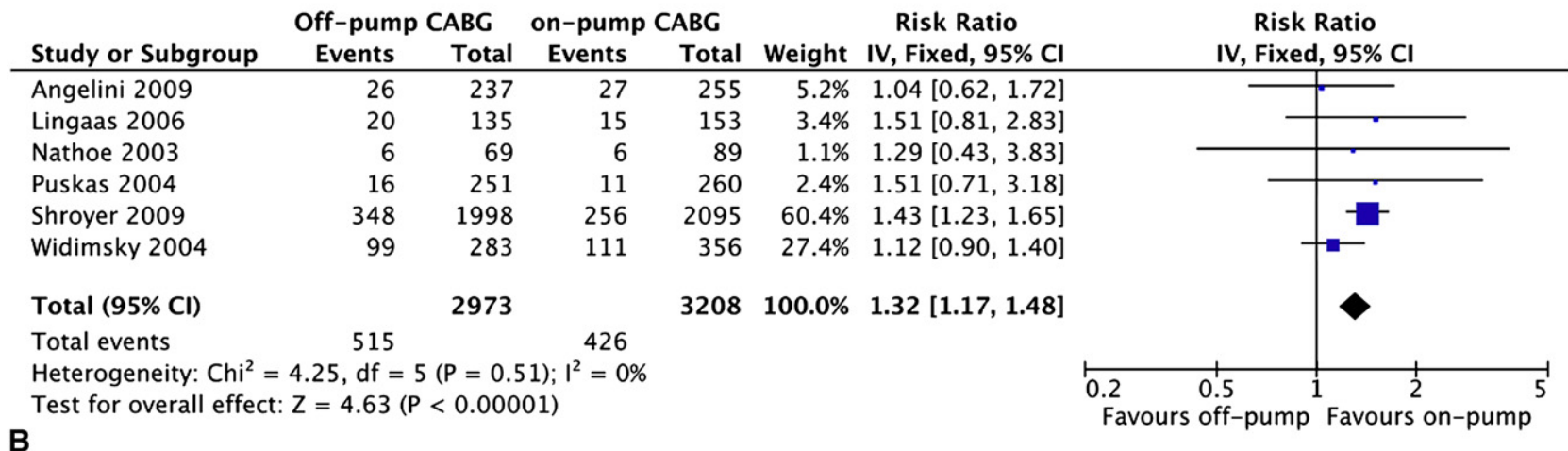

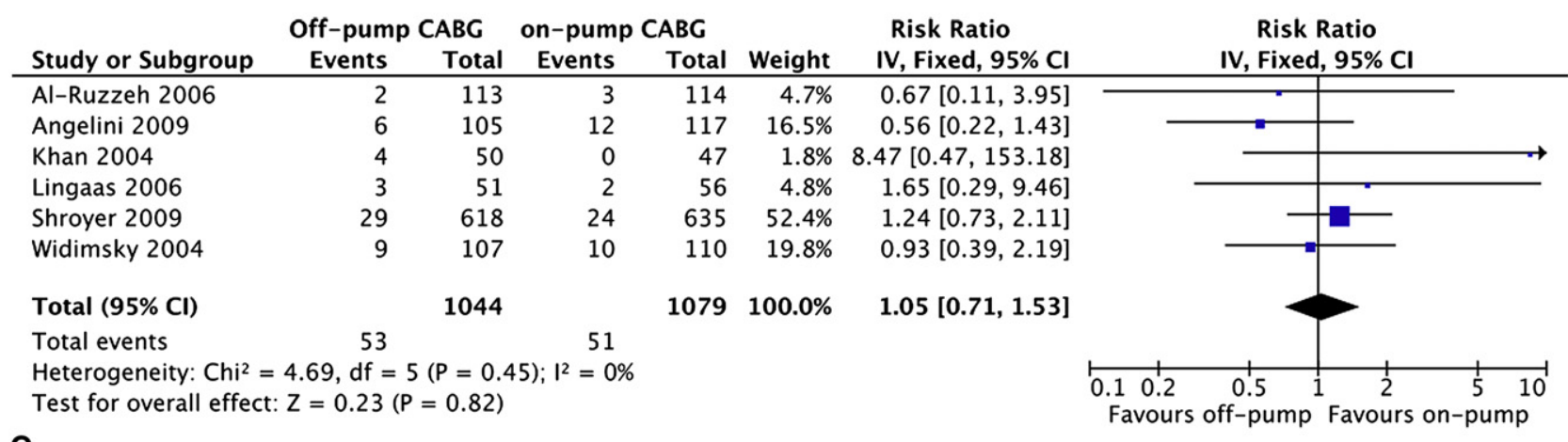

C

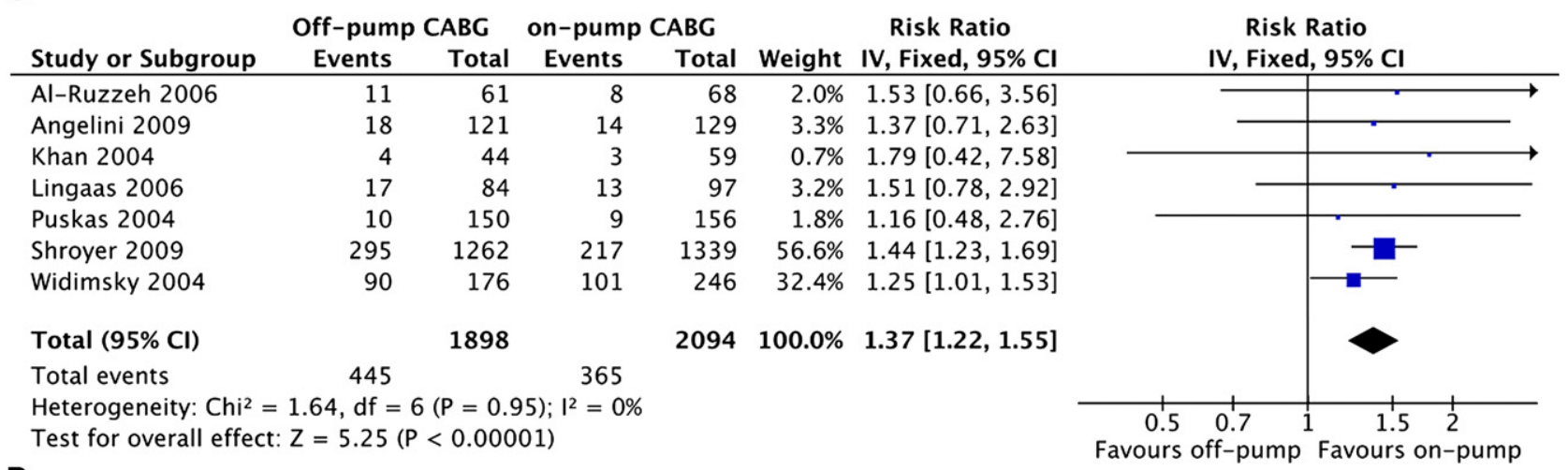

FIGURE 1. Forrest plot of overall graft occlusion risk among patients randomized to off-pump versus on-pump CABG in all studies (A) and studies reporting graft patency of 1 year or more (B). Forrest plot of internal thoracic artery (C) and saphenous vein (D) graft occlusion risk. $I V$, Inverse variance; $C I$, confidence interval. 
TABLE 1. Randomized trials included in the present meta-analysis

\begin{tabular}{|c|c|c|c|c|c|c|c|c|}
\hline & Al-Ruzzeh & Angelini & Khan & Lingaas & Nathoe & Puskas & Shroyer & Widimsky \\
\hline Reference & $\begin{array}{c}B M J . \\
2006 ; 332: \\
1365\end{array}$ & $\begin{array}{l}J \text { Thorac } \\
\text { Cardiovasc } \\
\text { Surg. } \\
2009 ; 137: \\
295-303\end{array}$ & $\begin{array}{l}\text { N Engl J } \\
\text { Med. } \\
\text { 2004;350: } \\
21-8\end{array}$ & $\begin{array}{l}\text { Ann Thorac } \\
\text { Surg. 2006;81: } \\
\quad 2089-96\end{array}$ & $\begin{array}{c}\text { N Engl J Med. } \\
\text { 2003;348: } \\
\text { 394-402 }\end{array}$ & $\begin{array}{l}\text { JAMA. } \\
\text { 2004;291: } \\
1841-9\end{array}$ & $\begin{array}{c}\text { N Engl J Med. } \\
\text { 2009;361: } \\
1827-37\end{array}$ & $\begin{array}{c}\text { Circulation. } \\
\text { 2004;110: } \\
3418-23\end{array}$ \\
\hline No. of patients & 168 & 401 & 103 & 120 & 110 & 197 & 2203 & 400 \\
\hline Follow-up & $3 \mathrm{mo}$ & $7 y$ & $3 \mathrm{mo}$ & $1 \mathrm{y}$ & $1 \mathrm{y}$ & $1 \mathrm{y}$ & $1 \mathrm{y}$ & $1 \mathrm{y}$ \\
\hline $\begin{array}{l}\text { Patients } \\
\text { undergoing } \\
\text { CAG, \% }\end{array}$ & 90 & $50^{\mathrm{a}}$ & 80 & 91 & 64 & 78 & 62 & 64 \\
\hline Intention to treat & No crossovers & Yes & Yes & Yes & Yes & Yes & Yes & No \\
\hline Events committee & Blinded & Blinded & Blinded & NR & Blinded & Blinded & Blinded & NR \\
\hline
\end{tabular}

$C A G$, Coronary angiography; $N R$, not reported. ${ }^{2}$ Patients undergoing multidetector computed tomographic coronary angiography.

estimate, the effects of off-pump CABG on graft patency were explored separately in studies with follow-up of 1 year or more. All analyses were conducted with Microsoft Excel version 11.5 (Microsoft Corp, Redmond, Wash) and Review Manager (RevMan) version 5.0 (Nordic Cochrane Centre, Copenhagen, Denmark).

\section{RESULTS}

Our search identified 8 results of prospective randomized controlled clinical trials that compared graft patency of 3 or more months after off-pump and on-pump CABG (Table 1). In total, our meta-analysis included data on 6898 grafts. Pooled analysis demonstrated a statistically significant $32 \%$ increase in overall graft occlusion in off-pump compared with on-pump CABG (fixed-effects RR, 1.32; 95\% CI, $1.18-1.48 ; P<.00001 ; P$ for heterogeneity $=.20$; Figure $1, A$ ). Exclusion of any single study from the analysis did not substantively alter the overall result of our analysis. Although the results seemed to be heavily influenced by Shroyer and colleagues' trial $^{3}$ (weight, 57.9\%), even eliminating the particular trial demonstrated a statistically significant $19 \%$ increase in overall graft occlusion in off-pump compared with on-pump CABG (fixed-effects RR, 1.19; $95 \%$ CI, 1.00 [1.0028] to $1.42 ; P=.05$ [0.465]; $P$ for heterogeneity $=.27)$. When data from 6 studies reporting graft patency of 1 year or more were pooled, off-pump CABG was associated with a $32 \%$ increase in overall graft occlusion compared with on-pump CABG. This increase remained statistically significant (fixed-effects RR, $1.32 ; 95 \%$ CI, $1.17-$ $1.48 ; P<.00001 ; P$ for heterogeneity $=.51$; Figure $1, B)$. Subanalyses demonstrated a statistically nonsignificant ben- efit of on-pump over off-pump CABG for internal thoracic artery graft patency (fixed-effects RR, 1.05; 95\% CI, $0.71-1.53 ; P=.82 ; P$ for heterogeneity $=.45$; Figure 1 , $C$ ) but a statistically significant $37 \%$ increase in saphenous vein graft occlusion in off-pump compared with on-pump CABG (fixed-effects RR, 1.37; 95\% CI, 1.22-1.55; $P<$ $.00001 ; P$ for heterogeneity $=.95$; Figure $1, D)$.

\section{CONCLUSIONS}

The results of our updated meta-analysis suggest that offpump CABG may increase overall graft occlusion by $32 \%$, especially saphenous vein graft occlusion by $37 \%$, over onpump CABG. In the largest trial by Shroyer and coworkers, ${ }^{3}$ patients in the off-pump group had worse composite outcomes (death from any cause, a repeat revascularization procedure, or a nonfatal myocardial infarction) at 1 year of follow-up. The worse outcomes might be due to lower graft patency after off-pump CABG. Except for the study by Angelini and associates ${ }^{2}$ with a 7 -year follow-up, the remaining 7 studies included in the present meta-analysis reported graft patency of 1 year of less. To confirm our results, longer-term graft patency from randomized trials of off-pump versus onpump CABG is needed.

\section{References}

1. Takagi H, Tanabashi T, Kawai N, Kato T, Umemoto T. Off-pump coronary artery bypass sacrifices graft patency: meta-analysis of randomized trials. J Thorac Cardiovasc Surg. 2007;133:e2-3.

2. Angelini GD, Culliford L, Smith DK, Hamilton MC, Murphy GJ, Ascione R, et al Effects of on- and off-pump coronary artery surgery on graft patency, survival, and health-related quality of life: long-term follow-up of 2 randomized controlled trials. J Thorac Cardiovasc Surg. 2009;137:295-303.

3. Shroyer AL, Grover FL, Hattler B, Collins JF, McDonald GO, Kozora E, et al. On-pump versus off-pump coronary-artery bypass surgery. N Engl J Med. 2009;361:1827-37. 